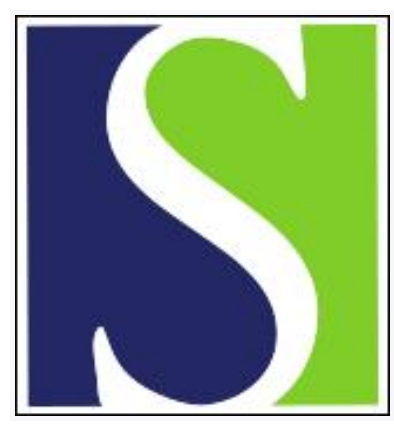

Scand J Work Environ Health 2005;31(1):75-81

https://doi.org/10.5271/sjweh.851

Issue date: Feb 2005

Impact of smoking policy on the respiratory health of food and beverage servers

by Dimich-Ward H, Lawson J, Hingston A, Chan-Yeung M

Affiliation: Respiratory Division, UBC Department of Medicine, VGH Research Pavilion, \#390-828 West 10th Avenue, Vancouver BC, Canada, V5Z 1L8. hward@interchange.ubc.ca

The following article refers to this text: 2008;34(4):267-277

Key terms: beverage server; environmental tobacco smoke; food server; hair nicotine; hospitality industry; lung function; respiratory health; respiratory symptom; smoking; smoking policy

This article in PubMed: www.ncbi.nlm.nih.gov/pubmed/15751622

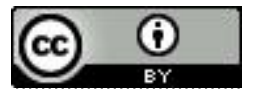




\title{
Impact of smoking policy on the respiratory health of food and beverage servers
}

by Helen Dimich-Ward, PhD, ${ }^{1}$ Joshua Lawson MSc, ${ }^{2}$ Adrian Hingston, BSc, ${ }^{3}$ Moira Chan-Yeung, MB ${ }^{1}$

\begin{abstract}
Dimich-Ward H, Lawson J, Hingston A, Chan-Yeung M. Impact of smoking policy on the respiratory health of food and beverage servers. Scand J Work Environ Health 2005;31(1):75-81.
\end{abstract}

\begin{abstract}
Objectives The purpose of this study was to determine whether workplace smoking policy was associated with respiratory health effects among food and beverage servers.

Methods Data were obtained from a postal survey of hospitality workers. The participation rate for the questionnaire was $73.9 \%$ of those contacted. Current smokers were excluded from the analysis. Adjustment for differences between groups in age, gender, ex-smoker versus never smoker status, home exposure environmental tobacco smoke, childhood asthma, mail versus telephone questionnaire, and hours worked per week was done using logistic regression. A subset of 88 nonsmokers underwent laboratory evaluation, including spirometry and hair nicotine analysis.

Results The prevalence of irritant and respiratory symptoms among 383 nonsmokers was consistently higher among the participants from premises where smoking was permitted without restrictions on the workplace. In comparison with those from facilities where smoking was prohibited, the highest adjusted odds ratios (OR) were for chronic phlegm for those working where smoking was permitted (OR $8.595 \%$ confidence interval (95\% CI) 2.4-30.0] or where there were partial smoking restrictions (OR 5.7 95\% CI 1.7-19.4). Lung function was not reduced apart from the ratio between forced expiratory volume in 1 second and forced vital capacity, which was lower for workers from facilities where smoking was permitted. Hair nicotine levels were lowest for workers from facilities where smoking was prohibited.

Conclusions The results suggest that occupational exposure to environmental tobacco smoke, determined through smoking policies, can adversely affect the respiratory health of nonsmokers who work in the food and beverage service industry.
\end{abstract}

Key terms environmental tobacco smoke; hair nicotine; hospitality industry; lung function; respiratory symptom.

Environmental tobacco smoke, or second hand smoke, is a complex mixture of an aged and diluted mixture of aerosols, vapors, and hundreds of chemical compounds from exhaled mainstream and side-stream smoke, including such respiratory irritants as sulfur dioxide, ammonia, and formaldehyde (1). According to the United States Environmental Protection Agency, environmental tobacco smoke is the most widespread and harmful indoor air contaminant and has been classified as a human (group A) lung carcinogen $(2,3)$.

The adverse health effects of exposure to environmental tobacco smoke on the health of children are well recognized and include a greater incidence of respiratory symptoms and asthma among schoolchildren whose parents smoke (4). For adults, the effects of exposure to environmental tobacco smoke are less obvious and may be dependent on the source of exposure. Hammond (5) reported typical workplace concentrations of nicotine up to 10 times higher than average home levels, leading her to conclude that a significant number of workers in the United States are exposed to hazardous levels of environmental tobacco smoke. Siegel (6) concluded that environmental tobacco smoke is "a significant occupational hazard for food service workers [p 490]" based on a review of occupational health studies showing increased risks of lung cancer among waiters.

1 University of British Columbia, Department of Medicine, Vancouver, Canada.

2 University of Alberta, Public Health Sciences, Edmonton, Canada.

3 University of British Columbia, School of Occupational and Environmental Hygiene, Vancouver, Canada.

Reprint requests to: Dr Helen Ward, Respiratory Division, UBC Department of Medicine, VGH Research Pavilion, \#390828 West 10th Avenue, Vancouver BC, Canada, V5Z 1L8. [E-mail: hward@interchange.ubc.ca] 
Hammond et al (7) found worksite smoking policy to have a major effect on nicotine concentrations, which increased from a median of $0.3 \mu \mathrm{g} / \mathrm{m}^{3}$ at worksites that banned smoking to $1.3 \mu \mathrm{g} / \mathrm{m}^{3}$ at sites that restricted smoking and to $8.6 \mu \mathrm{g} / \mathrm{m}^{3}$ at open offices at worksites that allowed smoking. The impetus for adopting increased smoking restrictions has been largely aimed towards the protection of the public, especially children, from health consequences associated with exposure to environmental tobacco smoke $(8,9)$. Employer liability is also becoming an increasing concern.

The purpose of this study was to determine the relationship between occupational exposure to environmental tobacco smoke as indicated by workplace smoking policy and the prevalence of irritant and respiratory symptoms among nonsmoking food and beverage service workers. An evaluation of the physiological basis for symptoms and exposure to environmental tobacco smoke was conducted using laboratory investigations.

\section{Study population and methods}

\section{Postal survey}

Ethical approval for the study was obtained by the University Clinical Ethics Review Committee. In the initial postal survey, conducted between February 1997 and February 1999, attempts were made to contact 2184 employees from 17 municipalities in the Vancouver area. Membership lists were obtained from a local union of bar workers, restaurant servers, and hotel workers. Potential participants were sent a letter explaining the purpose and procedures of the study, a self-addressed stamped envelope, and a questionnaire. Repeated attempts were made to contact nonrespondents by telephone and the use of reminder cards, followed by an additional questionnaire. By having the participants

Table 1. Participation rate for participants from the hospitality industry.

\begin{tabular}{lrrr}
\hline & \multicolumn{3}{c}{ Entire sample } \\
\cline { 2 - 4 } & & & \\
& & $\%$ \\
\cline { 2 - 4 } Questionnaires sent & 2184 & $\cdot$ \\
Unable to contact (invalid phone number, no answer) & 568 & $\cdot$ \\
Excluded (not in industry, retired, moved, language barrier) & 453 & $\cdot$ \\
Contacted and eligible & 1163 & 100 \\
Refusals & 303 & 26.1 \\
Mail survey participants & 860 & 73.9 \\
Nonsmokers & 557 & $\cdot$ \\
Food and beverage servers & 383 & $\cdot$ \\
Laboratory study participants & 160 & 55.9 \\
Nonsmoker food and beverage servers & 88 & $\cdot$ \\
\hline
\end{tabular}

complete the questionnaire away from the workplace, we attempted to ensure confidentiality. As shown in table 1 , questionnaires were completed by 860 participants. Upon the exclusion of smokers and those who did not work in the food and beverage industry, data from 382 participants were used for the analysis.

The postal questionnaire included questions on acute respiratory symptoms based on the questionnaire for asthma-like symptoms of the International Union Against Tuberculosis and Lung Diseases (10), but asked for information over the last 6 months. Questions regarding chronic respiratory symptoms, irritant symptoms, demographic variables, workplace characteristics, and the perception of smokiness were also included.

\section{Laboratory study}

A subset of the postal survey participants who resided in or nearby Vancouver were invited to participate in the laboratory portion of the study (participation rate of $55.9 \%$ ). Out of 160 participants in the laboratory study, data were included from 88 nonsmokers for which information on smoking policy in the food and beverage service industry was available.

Laboratory testing took place in 1998. After informed consent was obtained, a questionnaire-based interview and spirometry were performed. Spirometry was completed using standardized techniques recommended by the American Thoracic Society after the measurement of height and weight. A minimum of three acceptable forced expiratory maneuvers were performed using a computerized 10-liter dry rolling spirometer (S\&M instruments, Doylestown, PA, USA) with the participant seated and wearing a nose clip. Forced expiratory volume in the first second $\left(\mathrm{FEV}_{1}\right)$, forced vital capacity (FVC), and forced expiratory flow between $25 \%$ and $75 \%$ of the FVC $\left(\mathrm{FEF}_{25-75}\right)$ were measured and the $\mathrm{FEV}_{1} / \mathrm{FVC}$ ratio was computed. Prediction equations were based on data from Crapo et al (11).

A hair sample was obtained for the analysis of nicotine levels based on published protocols $(12,13)$. About $10 \mathrm{mg}$ of hair was cut close to the scalp at the posterior vertex of the head, to a maximum of $7.8 \mathrm{~cm}$ in length (representing approximately 6 months' exposure). The hair was weighed and processed for radioimmunoassay analysis (RIA) by a certified technician who was blinded to the participant's exposure group. The RIA used tritiated nicotine as the tracer, with specific antisera used at a titer of 1:300 and goat anti-rabbit gamma globulin as the precipitating antibody. For quantification, nicotine standards of 0.5 to $50 \mathrm{ng} / \mathrm{ml}$ were used. The hair was washed in ultrasonic baths for 30 minutes using dichloromethane, oven dried for several minutes, and then digested by adding $0.46 \mathrm{ml}$ of $1 \mathrm{~N}$ sodium hydroxide to each sample. Each sample was then capped and 
placed in the oven for 20 minutes at $100^{\circ}$ Celsius, then neutralized with $41.6 \mu \mathrm{l}$ of concentrated hydrochloric acid. RIA was performed using a 1:10 dilution. The lower limit of detection was $5 \mathrm{ng} / \mathrm{ml}$, and the upper limit of detection was $500 \mathrm{ng} / \mathrm{ml}$.

\section{Data analysis}

The questionnaires and data collection sheets were coded, checked, and keypunched using double-entry techniques. Descriptive data analysis was undertaken using the Statistical Package for the Social Sciences (SPSS Version 10.0, Chicago, IL, USA). Logistic regression was performed using STATA (version 6.0, College Station, TX, USA).

Current smokers, who responded positively to the questions "Have you ever smoked cigarettes regularly ( 1 or more per day for at least 1 year)?" and "Do you now smoke cigarettes?" were excluded from all the analyses, as were hospitality workers who were employed in hotels. Smoking status was confirmed for the laboratory participants. Workplace smoking policies were classified as "prohibited" (0\% of the workplace set aside for smokers), "restricted" (partial smoking restrictions), and "permitted" (smoking permitted in 100\% of the workplace). Regulations as to the percentage of smokers allowed in public facilities varied across the municipalities, but greater restrictions were placed on restaurants and other food establishments, in comparison with bars.

The following definitions were used to define the respiratory and irritant symptoms: (i) asthma-like symptoms occurring at any time in the last 6 months [ie, wheeze (had wheezing or whistling in the chest without a cold), awakened by dyspnea (had been awakened by an attack of shortness of breath), awakened by cough (had been awakened by an attack of coughing)], (ii) chronic respiratory symptoms [ie, chronic cough (had a cough on most days of the week for at least 3 months of the year), chronic phlegm (brought up phlegm on most days of the week for at least 3 months of the year)], and (iii) irritant symptoms [ie, burning or itchy eyes (burning or itchy eyes at least once a week while at work), burning or itchy skin (burning or itchy skin at least once a week while at work)].

The differences in the prevalence of symptoms and characteristics between the groups were evaluated using chi-square analysis and an analysis of variance (ANOVA). Multiple logistic regression techniques were used to compute odds ratios (OR) and 95\% confidence intervals $(95 \% \mathrm{CI})$ with symptom as the dependent variable. The analyses by workplace smoking policy group were adjusted for gender, age, childhood asthma, smoking status (ex-smoker for at least 1 year versus never smoker), household smoking, questionnaire type (mail versus telephone) and hours worked per week.

An analysis of the laboratory pulmonary function variables and the hair nicotine levels were undertaken using ANOVA for a comparison of the group means. Hair nicotine levels were log-transformed prior to the data analysis. Multiple regression techniques were applied to adjust the values for between-group differences in the confounders.

\section{Results}

\section{Postal study}

As seen in table 2, those working in facilities where smoking was permitted had a greater percentage of exsmokers and tended to work longer in the industry. The shortest workweek was for workers from facilities where smoking was prohibited. With fewer restrictions on smoking, there was an increase in the perception of smokiness and estimates of hours per day of exposure to environmental tobacco smoke. A $100 \%$ smoking ban was supported by the majority of respondents $(90.5 \%$, $63.3 \%$ and $53.7 \%$ for the smoking prohibited, restricted, and permitted groups, respectively).

Table 2. Personal and work characteristics for nonsmoking food and beverage servers according to workplace smoking policy.

\begin{tabular}{|c|c|c|c|c|c|c|c|c|c|c|c|c|c|c|}
\hline \multirow{3}{*}{$\begin{array}{l}\text { Workplace } \\
\text { smoking } \\
\text { policy }\end{array}$} & \multicolumn{6}{|c|}{ Workers' personal characteristics } & \multicolumn{8}{|c|}{ Workers' work-related characteristics } \\
\hline & \multicolumn{2}{|c|}{$\begin{array}{c}\text { Age } \\
\text { (years) }\end{array}$} & \multirow{2}{*}{$\begin{array}{c}\text { Gender } \\
\text { (fe- } \\
\text { male) } \\
(\%)\end{array}$} & \multirow{2}{*}{$\begin{array}{l}\text { Child- } \\
\text { hood } \\
\text { asthma } \\
(\%)\end{array}$} & \multirow{2}{*}{$\begin{array}{l}\text { Ex- } \\
\text { smok- } \\
\text { er } \\
(\%)\end{array}$} & \multirow{2}{*}{$\begin{array}{c}\text { Live } \\
\text { with a } \\
\text { smok- } \\
\text { er } \\
(\%)\end{array}$} & \multirow{2}{*}{$\begin{array}{c}\text { Smoki- } \\
\text { ness } \\
\text { (mod- } \\
\text { erate/ } \\
\text { heavy) } \\
(\%)\end{array}$} & \multirow{2}{*}{$\begin{array}{l}\text { Bar } \\
\text { work- } \\
\text { ers } \\
(\%)\end{array}$} & \multicolumn{2}{|c|}{$\begin{array}{l}\text { Years } \\
\text { in } \\
\text { job }\end{array}$} & $\begin{array}{l}\text { Years } \\
\text { in } \\
\text { industry }\end{array}$ & $\begin{array}{l}\text { Work- } \\
\text { hours/ } \\
\text { week }\end{array}$ & \multicolumn{2}{|c|}{$\begin{array}{c}\text { Exposure } \\
\text { (hours/ } \\
\text { day) }\end{array}$} \\
\hline & Mean & SD & & & & & & & Mean & SD & Mean SD & Mean SD & Mean & SD \\
\hline Prohibited ( $N=166)$ & 38.5 & 12.4 & 45.2 & 5.4 & 26.2 & 12.9 & 7.8 & 10.2 & 7.0 & 7.1 & 13.511 .3 & 28.212 .2 & 0.6 & 1.5 \\
\hline Restricted $(\mathrm{N}=136)$ & 40.0 & 12.4 & 48.5 & 3.8 & 38.5 & 20.9 & 55.1 & 44.9 & 7.7 & 6.9 & $14.8 \quad 9.4$ & 31.010 .6 & 5.1 & 2.9 \\
\hline Permitted $(\mathrm{N}=81)$ & 40.6 & 12.3 & 48.1 & 8.6 & 42.3 & 21.5 & 77.8 & 67.9 & 8.2 & 7.4 & 16.610 .5 & $31.6 \quad 11.2$ & 6.9 & 2.1 \\
\hline $\mathrm{P}$-value & 0.41 & . & 0.82 & 0.32 & 0.02 & 0.11 & 0.00 & 0.00 & 0.41 & . & 0.09 & 0.04 & 0.00 & . \\
\hline
\end{tabular}


The prevalence of respiratory and irritant symptoms in each of the groups is shown in figure 1. A higher prevalence of symptoms was consistently observed for those working where smoking was permitted. Reports of adult-onset asthma were found to be significantly higher for those working where smoking was permitted, at $13.6 \%$ in comparison with $5.9 \%$ and $3.6 \%$ for the smoking restricted and prohibited groups, respectively.

Table 3 presents odds ratios for the association between workplace smoking policy and symptoms adjusted for differences in age, gender, childhood asthma, exsmoking, household smoking, questionnaire type, and hours worked per week. Those working where smoking was restricted or permitted had over five times the risk of chronic phlegm in comparison with those working where smoking was prohibited. In addition, those working where there were no controls on smoking had an increased risk of wheeze and chronic cough. The adjusted odds ratio for adult-onset asthma was elevated but not statistically significant (OR 3.3, 95\% CI 0.97-11.4) for the smoking permitted category. The irritant symptom of burning or itchy eyes was significantly higher with work where smoking was either restricted or permitted.

\section{Laboratory study}

A comparison of the laboratory study participants with those who completed the postal survey (table 4) showed no differences in characteristics apart from the perception of exposure and the percentage of smoking allowed in the workplace, which were higher on the average for the laboratory participants. No significant differences in respiratory symptoms were found; however, the eye and skin irritant symptoms were higher in prevalence for the laboratory participants (data not shown).

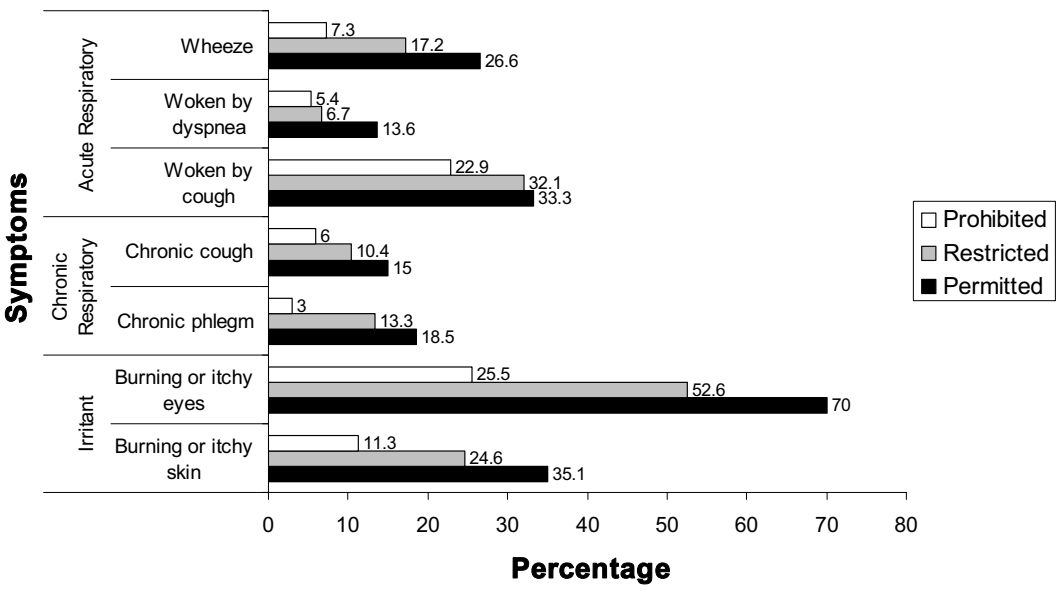

Figure 1. Raw prevalence of respiratory and irritant symptoms for nonsmoker food and beverage servers according to workplace smoking policy.

Table 3. Adjusted odds ratios a of symptoms for nonsmoking food and beverage servers according to workplace smoking policy.

\begin{tabular}{|c|c|c|c|c|c|c|c|c|c|c|c|c|c|c|}
\hline \multirow{2}{*}{$\begin{array}{l}\text { Workplace } \\
\text { smoking } \\
\text { policy }\end{array}$} & \multicolumn{2}{|c|}{ Wheeze } & \multicolumn{2}{|c|}{$\begin{array}{l}\text { Awakened } \\
\text { by dyspnea }\end{array}$} & \multicolumn{2}{|c|}{$\begin{array}{l}\text { Awakened } \\
\text { by cough }\end{array}$} & \multicolumn{2}{|c|}{$\begin{array}{l}\text { Chronic } \\
\text { cough }\end{array}$} & \multicolumn{2}{|c|}{$\begin{array}{l}\text { Chronic } \\
\text { phlegm }\end{array}$} & \multicolumn{2}{|c|}{$\begin{array}{l}\text { Burning or } \\
\text { itchy eyes }\end{array}$} & \multicolumn{2}{|c|}{$\begin{array}{l}\text { Burning or } \\
\text { itchy skin }\end{array}$} \\
\hline & $\mathrm{OR}$ & $95 \% \mathrm{Cl}$ & $\mathrm{OR}$ & $95 \% \mathrm{Cl}$ & $\mathrm{OR}$ & $95 \% \mathrm{Cl}$ & $\mathrm{OR}$ & $95 \% \mathrm{Cl}$ & $\mathrm{OR}$ & $95 \% \mathrm{Cl}$ & $\mathrm{OR}$ & $95 \% \mathrm{Cl}$ & $\mathrm{OR}$ & $95 \% \mathrm{Cl}$ \\
\hline Prohibited & 1.0 & . & 1.0 & . & 1.0 & . & 1.0 & $\cdot$ & 1.0 & . & 1.0 & $\cdot$ & 1.0 & $\cdot$ \\
\hline Restricted & 2.0 & $0.8-5.0$ & 0.6 & $0.2-1.9$ & 1.3 & $0.7-2.4$ & 2.0 & $0.7-5.8$ & 5.7 & $1.7-19.4$ & 2.5 & $1.4-4.5$ & 1.3 & $0.6-2.7$ \\
\hline Permitted & 3.8 & $1.5-9.4$ & 2.0 & $0.7-5.7$ & 1.5 & $0.7-3.0$ & 3.5 & $1.2-10.4$ & 8.5 & $2.4-30.0$ & 5.1 & $2.6-10.2$ & 2.1 & $0.9-4.9$ \\
\hline
\end{tabular}

${ }^{a}$ Adjusted for gender, age, childhood asthma, smoking status (ex-smoker versus never smoker), household smoking, questionnaire type (postal versus telephone) and hours worked per week.

Table 4. Comparison of characteristics of the laboratory participants with the postal survey participants.

\begin{tabular}{|c|c|c|c|c|c|c|c|c|c|c|c|c|c|c|c|c|}
\hline \multirow[t]{2}{*}{ Participants } & \multicolumn{2}{|c|}{$\begin{array}{c}\text { Age } \\
\text { (years) }\end{array}$} & \multirow[t]{2}{*}{$\begin{array}{c}\text { Gender } \\
\text { (female) } \\
(\%)\end{array}$} & \multirow[t]{2}{*}{$\begin{array}{l}\text { Child- } \\
\text { hood } \\
\text { asthma } \\
(\%)\end{array}$} & \multirow[t]{2}{*}{$\begin{array}{l}\text { Ex- } \\
\text { smok- } \\
\text { er } \\
(\%)\end{array}$} & \multirow[t]{2}{*}{$\begin{array}{c}\text { Live } \\
\text { with a } \\
\text { smoker } \\
(\%)\end{array}$} & \multicolumn{2}{|c|}{$\begin{array}{l}\text { Work- } \\
\text { hours/ } \\
\text { week }\end{array}$} & \multicolumn{2}{|c|}{$\begin{array}{l}\text { Years } \\
\text { in } \\
\text { job }\end{array}$} & \multicolumn{2}{|c|}{$\begin{array}{c}\text { Years } \\
\text { in } \\
\text { industry }\end{array}$} & \multicolumn{2}{|c|}{$\begin{array}{l}\text { Exposure } \\
\text { (hours/ } \\
\text { day) }\end{array}$} & \multicolumn{2}{|c|}{$\begin{array}{l}\text { Smoking } \\
\text { allowed }\end{array}$} \\
\hline & Mean & SD & & & & & Mean & SD & Mean & SD & Mean & SD & Mean & SD & $\%$ & SD \\
\hline Mail only (N=295) & 39.3 & 12.6 & 47.8 & 6.5 & 33.9 & 19.0 & 30.0 & 11.5 & 7.3 & 6.9 & 14.2 & 10.5 & 3.2 & 3.4 & 39.3 & 40.3 \\
\hline $\operatorname{Lab}(\mathrm{N}=88)$ & 40.1 & 11.8 & 44.3 & 2.3 & 33.7 & 12.6 & 30.0 & 11.6 & 8.0 & 7.9 & 16.0 & 10.5 & 4.4 & 3.4 & 53.6 & 43.3 \\
\hline P-value & 0.59 & 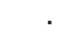 & 0.57 & 0.13 & 0.97 & 0.17 & 0.94 & 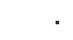 & 0.40 & & 0.17 & 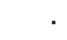 & 0.01 & & 0.00 & \\
\hline
\end{tabular}


Table 5. Laboratory results for the nonsmoking food and beverage servers according to workplace smoking policy. (FEV ${ }_{1}=$ forced expiratory volume in 1 second, FVC = forced vital capacity, $\mathrm{FEF}_{25-75}=$ forced expiratory flow ratio $25-75 \%$ of the FVC)

\begin{tabular}{|c|c|c|c|c|c|c|c|c|c|c|}
\hline \multirow{2}{*}{$\begin{array}{l}\text { Workplace } \\
\text { smoking } \\
\text { policy }\end{array}$} & \multicolumn{2}{|c|}{ Predicted FVC (\%) } & \multicolumn{2}{|c|}{ Predicted FEV ${ }_{1}(\%)$} & \multicolumn{2}{|c|}{ Predicted $\mathrm{FEF}_{25-75}(\%)$} & \multicolumn{2}{|c|}{$\mathrm{FEV}_{1} / \mathrm{FVC}$} & \multicolumn{2}{|c|}{ Hair nicotine (ng/mg hair) } \\
\hline & Mean & SD & Mean & SD & Mean & SD & $\%$ & SD & Geometric mean & SD \\
\hline Prohibited ( $N=22)$ & 104.8 & 14.3 & 103.0 & 14.8 & 90.8 & 25.1 & 81.1 & 5.4 & 1.4 & 2.1 \\
\hline Restricted (N=38) & 101.8 & 13.4 & 99.2 & 12.6 & 95.3 & 21.3 & 80.6 & 5.0 & 4.6 & 3.4 \\
\hline Permitted (N=28) & 109.1 & 14.2 & 104.2 & 14.6 & 88.7 & 24.5 & 77.8 & 5.0 & 5.4 & 4.7 \\
\hline P-value & 0.12 & . & 0.32 & . & 0.51 & . & 0.04 & $\cdot$ & 0.01 & $\cdot$ \\
\hline
\end{tabular}

The laboratory findings are shown in table 5. There were no significant differences between the smoking policy groups in the percentage of predicted FVC and $\mathrm{FEV}_{1}$ values, which, on the average, were at least $100 \%$ of the predicted. However, the ratio of $\mathrm{FVC} / \mathrm{FEV}_{1}$ was significantly lower among those working in facilities where smoking was permitted. With adjustment for differences in age, gender, race and height, ex-smoker versus never smoker status, number of years in the industry and usual number of hours per week worked, the coefficient of this group failed to reach statistical significance $(\mathrm{P}=0.07)$. Significantly lower levels of hair nicotine were found where smoking was prohibited. However, no relationship was found between hair nicotine levels and lung function (data not shown).

\section{Discussion}

Food and beverage workers who were nonsmokers employed in establishments that allowed smoking in 100\% of the premises had a greater prevalence of acute and chronic respiratory symptoms and of eye and skin irritation. In comparison with workers from facilities where smoking was prohibited, the highest risks $(\mathrm{OR}>5)$ were found for phlegm for workers where smoking was either restricted or permitted.

The majority of those working where the policy permitted smoking (68\%) was employed in bars. In a 1993 review by Siegel (6), respirable suspended particles measured in bars were three times higher than those taken in restaurants. Restaurant workers in dining restaurants had much lower exposure to environmental tobacco smoke, as measured by breathing-zone nicotine levels and by the quantification of cotinine and 3-hydroxycotinine in urine than workers in pubs and nightclubs (14). Bartenders who worked in single-room facilities have been found to have the highest personal exposures to respirable particulates and nicotine of all the occupations studied (including professional, service industry, clerical and other white-collar workers) (15).

In a recent review of the literature, Jaakkola \& Jaakkola (16) concluded that the strongest evidence for a causal relation exists for environmental tobacco smoke and chronic respiratory symptoms (16). The European Respiratory Health Survey of 7882 adults aged 20 to 48 years showed that reporting work exposure to environmental tobacco smoke was related to a higher risk of asthma (OR 1.9, 95\% CI 1.25-2.88); there was no significant relationship with the reporting of exposure to home environmental tobacco smoke (17). The relative odds for chronic bronchitis was increased for work exposure to environmental tobacco smoke (OR 1.90, 95\% CI 1.16-3.11) in an analysis of data from 1890 German adults within the European Community Respiratory Health Survey (18). Eisner et al (19) found that both lower-level and higher-level environmental tobacco smoke exposures, based on personal nicotine badge measurements, were associated with increased risk of sensory symptoms and of respiratory symptoms (19). According to our study, food and beverage servers who were exposed to high levels of environmental tobacco smoke in their jobs, as determined by workplace smoking policy, had higher risks for symptoms consistent with asthma and chronic bronchitis. They had over five times the risk of chronic phlegm, almost a fourfold risk of wheeze without a cold, and over three times the risk of chronic cough when compared with those working where smoking was prohibited. Chronic phlegm was the only respiratory symptom found to be elevated for subjects from facilities with restricted smoking policies, although there were indications of increased risks for wheeze and chronic cough.

It has been reported that the most common acute effects from exposure to environmental tobacco smoke are sensory irritation of the eyes, nose, throat, and airways that tend to be enhanced with both increasing concentration and increasing duration of exposure (20). Study participants where smoking was permitted were over five times more likely to have itchy eyes and twice as likely to have itchy skin as those with the lowest exposure.

For the small sample of food and beverage workers who underwent spirometry, a slightly lower $\mathrm{FEV}_{1} / \mathrm{FVC}$ ratio was noted for the group for which smoking was permitted at work. However, the FVC and $\mathrm{FEV}_{1}$ values averaged just over $100 \%$ of the predicted values, 
perhaps indicating a healthy worker selection effect. A California study of 53 bartenders found decreased respiratory and sensory irritation symptoms and an improvement in the mean $\mathrm{FEV}_{1}$ and $\mathrm{FVC}$ a few months after the implementation of a legislative ban on smoking when compared with levels prior to the ban (21). Cross-sectional studies on the effects of workplace exposure to environmental tobacco smoke on lung function have shown contradictory results. There was a significantly lower percentage of predicted $\mathrm{FEV}_{1}, \mathrm{FVC}$, and $\mathrm{FEF}_{25-75}$ observed for Iranian men exposed to environmental tobacco smoke, the greatest adverse effect of exposure to environmental tobacco smoke being found for the men who were exposed at various types of workplaces (22). Recently, Chen and his colleagues (23) reported that never smokers highly exposed to environmental tobacco smoke at work had reduced $\mathrm{FEV}_{1}$ and FVC. An analysis of the ratio of the two lung function parameters was not reported. In contrast, a large crosssectional study of office workers (24) found very few differences in lung function according to exposure to environmental tobacco smoke.

Hair nicotine levels were lowest for those working where smoking was prohibited; this finding confirmed that occupational exposure to environmental tobacco smoke was related to workplace smoking policy. A recent study of 114 food and beverage servers from bars and restaurants found hair nicotine levels of nonsmokers to be highly related to workplace smoking policy (25). Similarly, a previous study of 26 persons showed a significant exposure gradient of nicotine in hair that was highest for those working in bars where there were no public smoking restrictions (13).

Despite evidence that smoking restrictions do not have a negative impact on restaurant sales (26), there is often resistance within the hospitality industry and within segments of the population to increase the restriction or eliminate smoking in public eating establishments. However, surveys of employee attitudes have generally shown that the majority support smoking restrictions in the workplace (27). Heloma \& Jaakkola (28) found that a nationally implemented some-free workplace law was associated with steadily reducing exposure to environmental tobacco smoke at work and found both smokers' and nonsmokers' attitudes shifting towards favoring a total ban on smoking at work. We found that the majority of workers surveyed supported a 100\% smoking ban, ranging from almost all of those working in facilities where smoking was prohibited to just over onehalf of those working where smoking was allowed throughout the premises.

Our study has several limitations associated with the cross-sectional design, including recall and selection biases. Although statistical adjustment was made to account for differences in distribution for several potential confounders, there remains the possibility of effects due to unmeasured confounders or effect modifiers, such as exposure to alcohol, smoking nontobacco products, and other factors possibly related to the lifestyle of bar workers as opposed to restaurant workers. The outcomes for the postal survey were based on the reporting of symptoms, and such surveys are subject to inaccuracy, particularly when there may be an awareness of negative health effects being associated with exposure to environmental tobacco smoke. The quantitative measures of lung function showed only slight and inconsistent differences between the groups.

Exposure based on current smoking policy is subject to misclassification of the extent of past and present occupational exposure to environmental tobacco smoke. The more objective measure of hair nicotine levels confirmed that increased long-term exposure to environmental tobacco smoke was found for food and beverage service workers where $100 \%$ of the workplace was designated for smoking. No exposure-response relationships of hair nicotine and lung function were found, although the analysis was hindered by a small group sample size and a low response rate. Workplace smoking policies have been shown to clearly make a substantial difference in the concentration of environmental tobacco smoke in the workplace $(5,7)$. An Ontario study of 180 public sites determined that 1 year after the implementation of smoking restrictions, there was an overall decrease in environmental tobacco smoke of about twothirds across all the sites tested (29).

In conclusion, we found a significantly higher prevalence of respiratory and sensory irritation symptoms among nonsmokers who work in food and beverage service facilities where there were few restrictions on smoking. Objective testing of health outcomes of a larger sample of persons, more refined exposure assessment, and a longitudinal study of changes in the health status of workers with changes in exposure are recommended to investigate further the occupational health risks related to exposure to environmental tobacco smoke at levels typically found in the hospitality industry.

\section{Acknowledgments}

We would like to thank Henry Chan for the hair nicotine measurements and Anne DyBuncio for the data programming. This study could not have been undertaken without the co-operation of Local 40 of the Hotel Restaurant Culinary Workers \& Bartenders Union.

Financial support for the project was provided by the BC Health Research Foundation, the National Health Research Development Program and the BC Lung Association. Salary support for Dr Dimich-Ward was 
provided by a BC Lung Association/CIHR Investigator Award.

\section{References}

1. Dimich-Ward H, Brauer M. Environmental tobacco smoke in restaurants: exposures and health effects. In: Watson RR, Witten M, editors. Environmental tobacco smoke. Boca Raton (FL): CRC Press; 1992. p 279-87.

2. US Environmental Protection Agency. Respiratory health effects of passive smoking: lung cancer and other disorders. Bethesda (MD): US Department of Health, Public Health Service, National Institute of Health; 1993. Smoking and Tobacco Control Monograph No 4; NIH publication no 933605 .

3. Jinot J, Bayard S. Respiratory health effects of passive smoking: EPA's weight of evidence analysis. J Clin Epidemiol 1994;47:339-49.

4. Cook DG, Strachan DP. Health effects of passive smoking, 3: parental smoking and prevalence of respiratory symptoms and asthma in school age children. Thorax 1997;52:1081-94.

5. Hammond SK. Exposure of U.S. workers to environmental tobacco smoke. Environ Health Perspect 1999;107 suppl 2:329-41.

6. Siegel M. Involuntary smoking in the restaurant workplace: a review of employee exposure and health effects. JAMA 1993;270:490-3.

7. Hammond SK, Sorensen G, Youngstrom R, Ockene JK. Occupational exposure to environmental tobacco smoke. JAMA 1995;274:956-60.

8. Tager IB, Weiss ST, Rosner B, Speizer FE. Effect of parental cigarette smoking on the pulmonary function of children. Am J Epidemiol 1979;110:15-26.

9. Tager IB, Weiss ST, Munoz A, Rosner B, Speizer FE. Longitudinal study of the effects of maternal smoking on the pulmonary function of children. N Engl J Med 1983;309:699-703.

10. Burney PG, Laitinen LA, Perdrizet S, Huckauf H, Tattersfield AE, Chinn S, et al. Validity and repeatability of the IUATLD (1984) Bronchial Symptoms Questionnaire: an international comparison. Eur Respir J 1989;2:940-5.

11. Crapo RO, Morris AH, Gardner RM. Reference spirometric values using techniques and equipment that meet ATS recommendations. Am Rev Respir Dis 1981;123:659-64.

12. Eliopoulos C, Klein J, Phan K, Knie B, Greenwald M, Chitayat $\mathrm{D}$, et al. Hair concentrations of nicotine and cotinine in women and their newborn infants. JAMA 1994;271:621-3.

13. Dimich-Ward H, Gee H, Brauer M, Leung V. Analysis of nicotine and cotinine in the hair of hospitality workers. J Occup Environ Med 1997;39:946-8.

14. Johnsson T, Tuomi T, Hyvärinen M, Svinhufvud J, Rothberg $\mathrm{M}$, Reijula K. Occupational exposure of non-smoking restau- rant personnel to environmental tobacco smoke in Finland. Am J Ind Med 2003;43:523-31.

15. Jenkins RA, Counts RW. Occupational exposure to environmental tobacco smoke: results of two personal exposure studies. Environ Health Perspect 1999;107 suppl 2:341-8.

16. Jaakkola MS, Jaakkola JJK. Effects of environmental tobacco smoke on the respiratory health of adults. Scand J Work Environ Health 2002;28 suppl 2:52-70.

17. Janson C, Chinn S, Jarvis D, Zock JP, Toren K, Burney P. Effect of passive smoking on respiratory symptoms, bronchial hyperresponsiveness, lung function and total serum $\operatorname{IgE}$ in the European Community Respiratory Health Survey: a crosssectional study. Lancet 2001;358:2103-9.

18. Radon K, Busching K, Heinrich J, Wichmann HE, Jorres RA, Magnusson $\mathrm{H}$, et al. Passive smoking exposure: a risk factor for chronic bronchitis and asthma in adults? Chest 2002;122:1086-90.

19. Eisner MD, Katz PP, Yelin EH, Hammond SK, Blanc PD. Measurement of environmental tobacco smoke exposure among adults with asthma. Environ Health Perspect 2001;109:809-15.

20. Tredaniel J, Boffetta P, Saracci R, Hirsch A. Exposure to environmental tobacco smoke and adult non-neoplastic respiratory diseases. Eur Respir J 1994;7:73-85.

21. Eisner MD, Smith AK, Blanc PD. Bartenders respiratory health after establishment of smoker-free bars and taverns. JAMA 1998;20:1904-14.

22. Masjedi MR, Kazemi H, Johnson DC. Effects of passive smoking on the pulmonary function of adults. Thorax 1990; 45:27-31.

23. Chen R, Tunstall-Pedoe H, Tavendale R. Environmental tobacco smoke and lung function in employees who never smoked: the Scottish MONICA study. Occup Environ Med 2001;58:563-8.

24. Kentner M, Triebig G, Weltle D. The influence of passive smoking on pulmonary function - a study of 1,351 office workers. Prev Med 1984;13:656-9.

25. Al-Delaimy W. Nicotine in hair of bar and restaurant workers. N Z Med J 2001;114:80-3.

26. Glantz S, Smith L. The effect of ordinances requiring smokefree restaurants on restaurant sales. Am J Public Health 1994;84:1081-5.

27. Broder I, Pilger C, Corey P. Environment and well being before and after smoking ban in office buildings. Can J Public Health 1993;84:254-8.

28. Heloma A, Jaakkola MS. Four-year follow-up of smoke exposure, attitudes and smoking behaviour following enactment of Finland's national smoke-free work-place law. Addiction 2003;98:1111-7.

29. Abernathy TB, O'Grady B, Dukeshire S. Changes in ETS following anti-smoking legislation. Can J Public Health 1998;89:33-4.

Received for publication 29 December 2003 